\title{
ANALISIS STRUKTUR LAPISAN BAWAH PERMUKAAN DENGAN METODE GEOLISTRIK DALAM PERENCANAAN PONDASI
}

\author{
Meriana Wahyu Nugroho, Fatma Ayu Nuning Farida A, Khodijah Maya \\ Dosen Universitas Hasyim Asy’ari Tebuireng Jombang
}

Email:wahyu@ringin-contong.com; fatmaayu2511@gmail.com

\begin{abstract}
The purpose of this study was to determine the structure of the subsurface at construction site Campus Rector Building B University Hasyim Ashari. Information subsurface structure used as the initial study foundation design. The research was carried out with resistivity geoelectric method using a resistivity meter. Interpretation of the track point J.01 - J.02 - J.03 known subsurface water dominated by basalt rocks, and discovered the hard ground at a depth of $12 \mathrm{~m}$ for planning the foundation beams, while on the track J.04 - J.02 - J.05 dominated by conglomerates and basalt rocks, and discovered the hard ground at a depth of $7 \mathrm{~m}$ to pile foundation design.
\end{abstract}

Keywords: layer structure, geoelectric, resistivity, foundation

\section{PENDAHULUAN}

Peningkatan mahasiswa dan kebutuhan ruangan juga tidak bisa dihindari. Untuk menunjang hal tersebut, pembangunan gedung baru merupakan langkah yang tepat. Namun masalah yang dihadapi sekarang adalah bagaimana merancang bangunan yang kuat, tahan lama, dan tepat guna. Kuat dan kokohnya suatu bangunan tidak hanya dipengaruhi oleh jenis, struktur dan material bangunan yang dipakai, namun kekuatan pondasi juga menentukan.

Ada dua syarat utama yang harus ditekankan dalam pembuatan pondasi yaitu pertama, pondasi harus mencapai tanah keras, yang kedua apabila tidak ditemukan tanah keras maka harus dilakukan pemadatan/perbaikan tanah. Kedua syarat diatas menjadi dasar diperlukannya mengetahui jenis pondasi yang baik dengan perencanaan yang tepat, dan strukur lapisan bawah yang akan dibangun. Metode geolistrik merupakan metode geofisika yang efektif digunakan untuk eksplorasi dangkal. Metode ini digunakan untuk mengetahui keadaan geologi bawah permukaan bumi melalui resistivitas batuan sehingga pondasi yang tepat dapat direncanakan dengan baik.

\section{DASAR TEORI}

Geolistrik adalah salah satu metode geofisika yang mempelajari sifat aliran listrik di dalam bumi begitu juga cara mendeteksinya di dalam dan di permukaan bumi. Meliputi pengukuran potensial, arus dan medan elektromagnetik yang terjadi baik secara alamiah maupun akibat injeksi arus ke dalam bumi. Pada metode geolistrik resistivitas (tahanan jenis), arus listrik diinjeksikan kedalam bumi melalui dua elektroda arus. Kemudian beda potensial yang terjadi diukur melalui dua elektroda potensial. Dari hasil pengukuran arus $(I)$ dan beda potensial $(V)$ untuk setiap jarak elektroda yang berbeda lalu dapat diturunkan variasi harga hambatan jenis masing-masing lapisan di bawah titik ukur (sounding point).

Pengukuran resistivitas batuan diperoleh dengan mengasumsikan bumi sebagai medium homogen isotropis. Asumsi ini menganggap perbedaan resistivitas dan ketebalan medium adalah homogen isotropis sehingga resistivitas yang terukur adalah resistivitas semu(apparent resistivity). Namun, kenyataannya bumi sebagai medium mempunyai perbedaan lapisan dengan resistivitas yang berbeda untuk setiap lapisannya. Oleh sebab itu, nilai resistivitas sebenarnya berkaitan dengan resistivitas semu $(\rho)$.

$$
\rho=K \frac{\Delta V}{I}
$$

Dengan $K$ adalah faktor geometri susunan elektroda yang nilainya bergantung 
pada posisi atau letak dua elektroda arus dan dua elektroda potensial dari konfigurasi yang

digunakan dalam pengukuran.

\begin{tabular}{lll}
\hline \multicolumn{3}{c}{ NilaiTahananJenis/Resistivitas Beberapa Material } \\
\hline Material & $\begin{array}{l}\text { Resistivity } \\
(\Omega \mathbf{m})\end{array}$ & $\begin{array}{l}\text { Conductivity } \\
(\mathbf{1} / \Omega \mathbf{m})\end{array}$ \\
\hline $\begin{array}{lll}\text { Igneous and metamorphic } \\
\text { Granite (Granit) }\end{array}$ & $5 \times 10^{3}-10^{6}$ & $10^{-6}-2 \times 10^{-4}$ \\
\hline Basalt (Basal) & $10^{3}-10^{6}$ & $10^{-6}-10^{-3}$ \\
\hline Slate (Sabak) & $6 \times 10^{2}-4 \times 10^{7}$ & $2.5 \times 10^{-8}-7 \times 10^{-3}$ \\
\hline Marble (Marmer) & $10^{2}-2.5 \times 10^{8}$ & $4 \times 10^{-9}-10^{-2}$ \\
\hline $\begin{array}{l}\text { Quartzite (Kuarsa) } \\
\text { Sedimentary Rock }\end{array}$ & $10-2 \times 10^{8}$ & $5 \times 10^{-9}-10^{-2}$ \\
\hline Sandstone (Batu Pasir) & $8-4 \times 10^{5}$ & $2.5 \times 10^{-4}-0.125$ \\
\hline $\begin{array}{l}\text { Shale (Serpih) } \\
\text { Limestone } \\
\text { Gamping) }\end{array}$ & $20-2 \times 10^{8}$ & $5 \times 10^{-4}-0.05$ \\
\hline
\end{tabular}

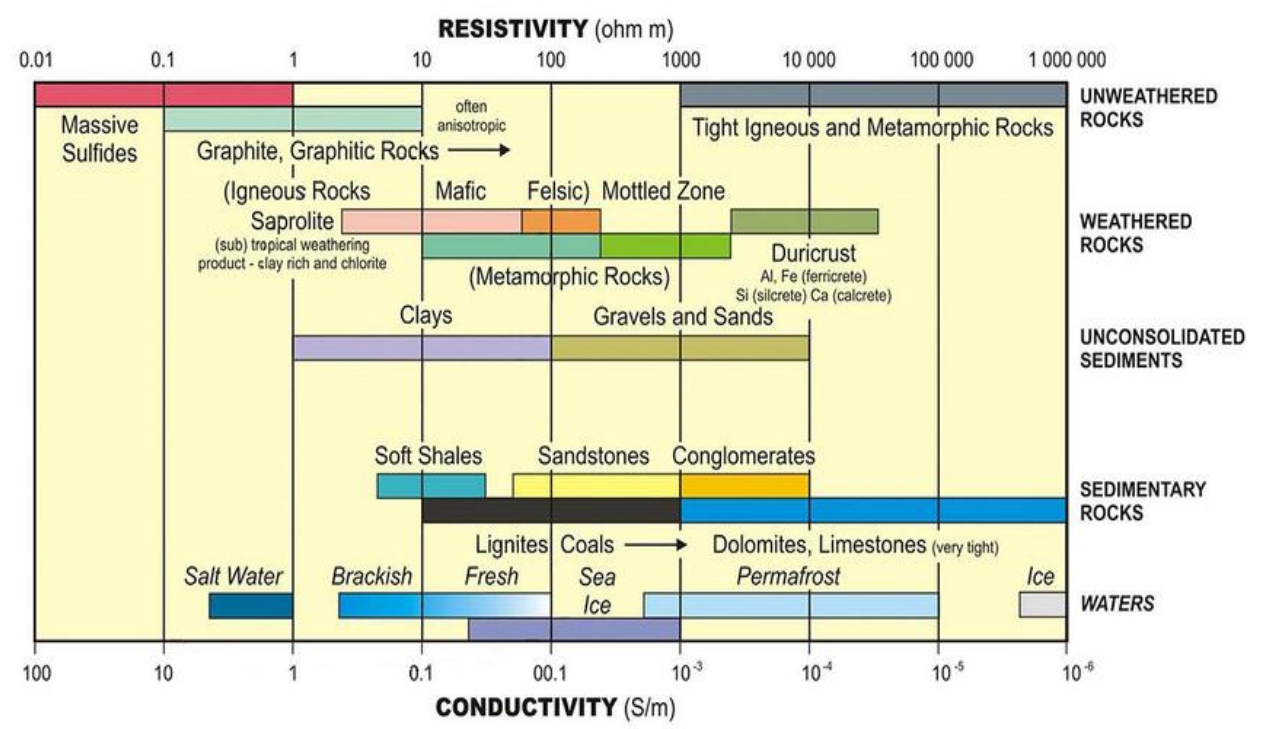

Gambar Skema Warna dan Nilai Resistivitas Mineral

Panjang Gelombang Warna

\begin{tabular}{ll}
\hline Warna & $\wedge(\mathrm{nm})$ \\
\hline Ungu & $380-450$ \\
\hline Biru & $450-495$ \\
\hline Hijau & $495-570$ \\
\hline Kuning & $570-590$ \\
\hline Jingga & $590-620$ \\
\hline Merah & $620-750$
\end{tabular}

Semakin tinggi panjang gelombang semakin tinggi nilai kerapatan lapisannya. Tahanan jenis batuan yang ada di berbagai macam komposisi mineral di bumi tidak mempunyai harga tahanan jenis tertentu akan tetapi nilainya mempunyai jangkauan (range) tertentu. Secara teoritis setiap batuan mempunyai daya hantar listrik dan harga tahanan jenisnya masing - masing. Batuan yang sama belum tentu memiliki nilai tahanan jenis yang sama. Sebaliknya harga tanahan jenis yang sama bisa dimiliki oleh batuan yang berbeda jenis. Faktor-faktor yang mempengaruhi nilai tahanan jenis antara lain : komposisi mineral padabatuan, kondisi batuan, komposisi bendacair pada batuan, dan factor ekstemal lainnya. 


\section{METODE PENELITIAN}

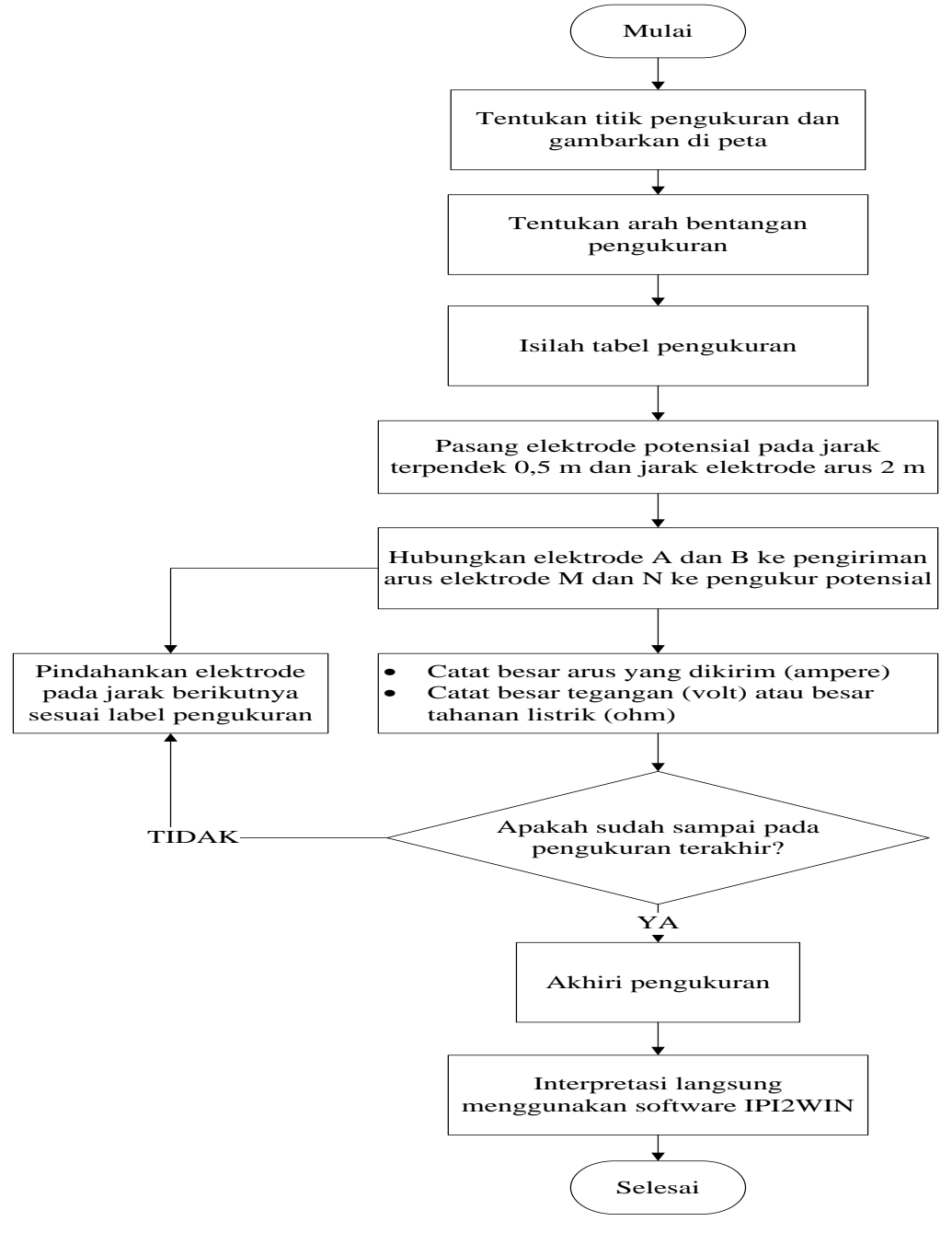

Pengambilan data dilakukan dengan alat resistivity meter di lima titik lintasan dengan bentang $100 \mathrm{~m}^{2}$ perlintasan. Kemudian nilai arus (I) dan beda potensial (V) yang geolistrik dan dinterpretasikan dengan aplikasi IPI2WIN. Hasil Interpretasi dibagi menjadi dua penampang lintasan yaitu J.01 - J.02 didapat diolah menggunakan pengolah data Lokasi Penelitian

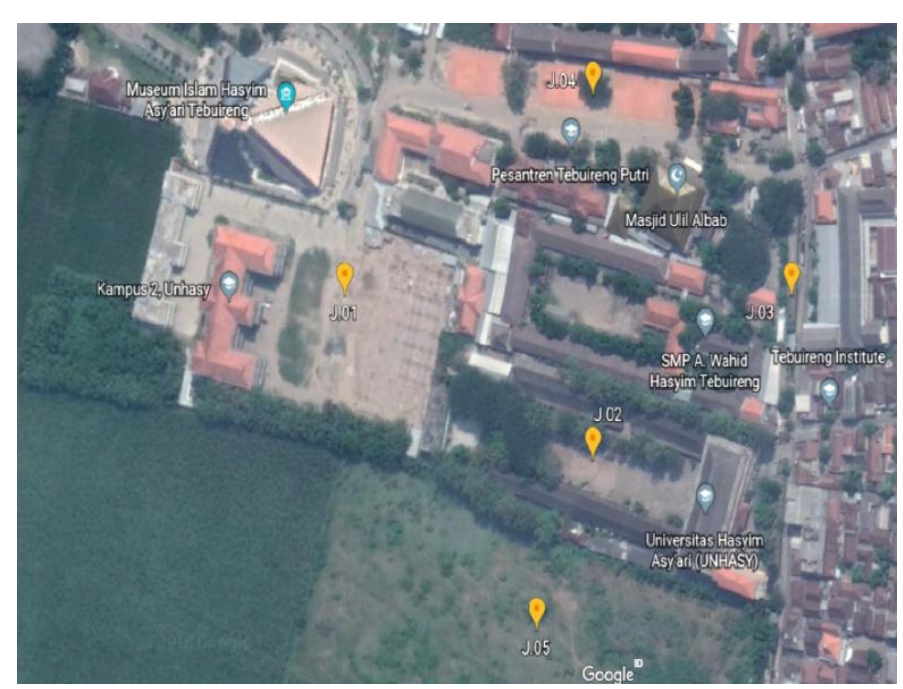


Lokasi J.01 terletak di koordinat S07॰36'33,5" - E112॰14'5,9"sepanjang $50 \mathrm{~m}$ ke utara dan $50 \mathrm{~m}$ ke selatan. Lokasi J.02 terletak koordinatS07॰36'35,8"

E112 ${ }^{\circ} 14^{\prime} 10,3 "$ sepanjang $50 \mathrm{~m}$ ke barat dan $50 \mathrm{~m}$ ke timur. Lokasi J.03 terletak di koordinat $\mathrm{S} 07 \circ 366^{\prime} 33,5$

E112॰14'13,8"sepanjang $50 \mathrm{~m}$ ke utara dan 50 $\mathrm{m}$ ke selatan. Lokasi J.04 terletak di koordinat S07॰36'30,7" - E112॰14'10,3" sepanjang $50 \mathrm{~m}$ ke barat dan $50 \mathrm{~m}$ ke timur. Lokasi J.05 terletak di koordinatS07॰36'38,2" - E $112^{\circ} 14^{\prime} 9,3^{\prime \prime}$ sepanjang $50 \mathrm{~m}$ ke barat dan $50 \mathrm{~m}$ ke timur.

\section{HASIL DAN PEMBAHASAN}

Setelah diperoleh data beda potensial $(V)$ dan arus (I) pada lima titik lintasan maka dihasilkan dua penampang lintasan crosssection yaitu lintasan J.01 - J.02 - J.03 dan J.04 - J.02 - J.05.

Lintasan J.01 - J.02 - J.03

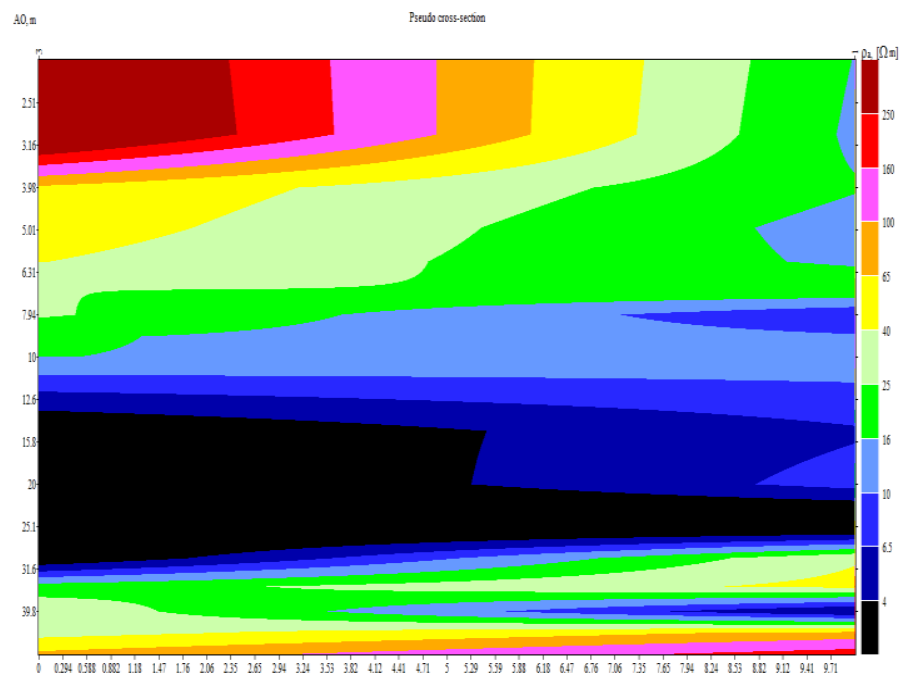

Grafik Pseudo Cross - Section Lapisan Bawah Permukaan Lintasan J.01 - J.02 - J.03

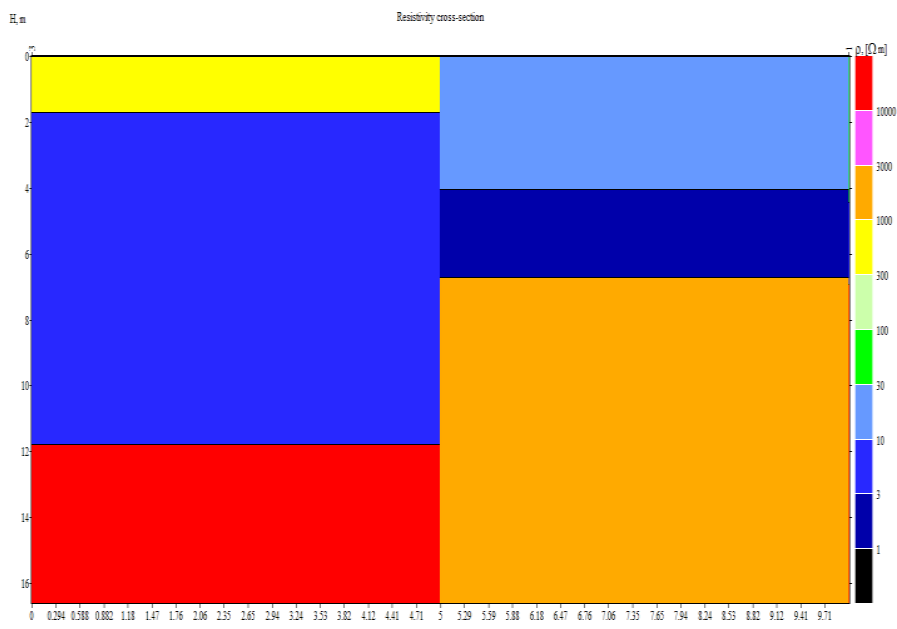

Grafik Resistivity Cross - Section Lapisan Bawah Permukaan Lintasan J.01 - J.02 - J.03 
Berdasarkan grafik diatas diketahui rentang nilai resistivitas lapisan berkisar antara $1-10000 \Omega \mathrm{m}$ dengan kedalaman mencapai $16 \mathrm{~m}$. Menurut hasil pendugaan pada kedalaman $0-2 \mathrm{~m}$ dengan resistivitas $300-1000 \Omega \mathrm{m}$ terdapat lapisan batuan serpih (limestone), namun juga terdapat lapisan air permukaan dengan nilai resisitivitas $10-30$ $\Omega \mathrm{m}$ hingga kedalaman $4 \mathrm{~m}$. Kemudian pada kedalaman $4 \mathrm{~m}$ terdapat lapisan air tanah hingga kedalaman $10 \mathrm{~m}$ dengan nilai resisitivitas $3-10 \Omega \mathrm{m}$, namun juga terdapat lapisan lempung dengan nilai resisitivitas 1 $3 \Omega \mathrm{m}$ hingga kedalaman $6 \mathrm{~m}$, kemudian lapisan batuan basalt hingga kedalaman $16 \mathrm{~m}$. Selain lapisan batuan basalt, juga terdapat lapisan batuan granit di kedalaman $16 \mathrm{~m}$ dengan nilai resistivitas $\geq 10^{4} \Omega \mathrm{m}$.

\section{Lintasan J.04 - J.02 - J.05}

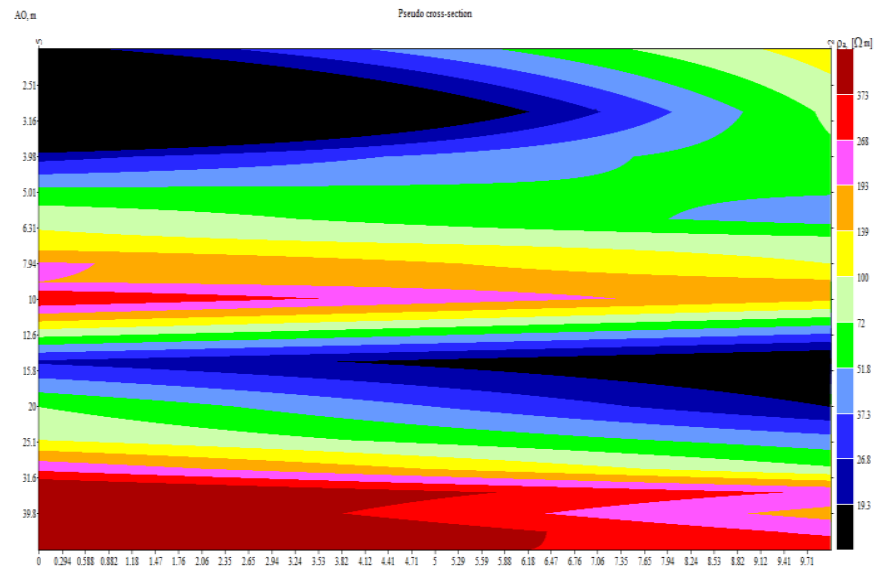

Grafik Pseudo Cross - Section Lapisan Bawah Permukaan

Lintasan J.04 - J.02 - J.05

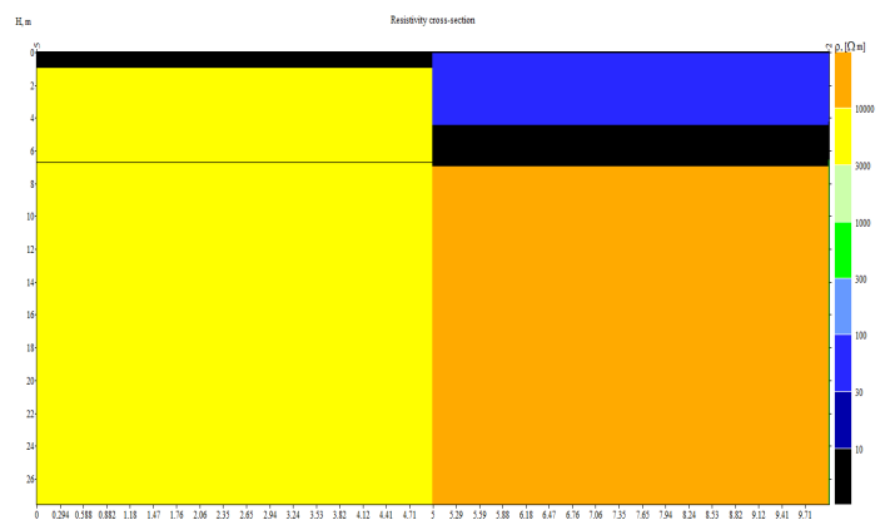

Grafik Resistivity Cross - Section Lapisan Bawah Permukaan Lintasan J.04 - J.02 - J.05

Berdasarkan grafik diatas diketahui rentang nilai resistivitas lapisan berkisar antara $10-10000 \Omega \mathrm{m}$ dengan kedalaman mencapai $26 \mathrm{~m}$. Menurut hasil pendugaan pada kedalaman $0-4 \mathrm{~m}$ terdapat lapisan air dengan nilai resistivitas $30-100 \Omega \mathrm{m}$, namun pada kedalaman $2-26 \mathrm{~m}$ juga terdapat lapisan batuan konglomerat dengan nilai resistivitas $300-10^{4} \Omega \mathrm{m}$. Pada kedalaman 7 -
$26 \mathrm{~m}$, terdapat lapisan batuan basalt dengan nilai resistivitas $\geq 10^{4} \Omega \mathrm{m}$.

\section{KESIMPULAN}

Hasil dari pendugaan struktur lapisan bawah permukaan dengan metode geolistrik adalah pada lintasan J.01 - J.02 - J.03 didominasi oleh batuan basalt dan air, serta ditemukan lapisan tanah keras pada kedalaman $12 \mathrm{~m}$, sehingga dapat direncanakan 
pondasi tiang. Pada lintasan J.04 - J.02 - J.05 didominasi oleh batuan konglomerat dan batuan basalt, serta pada kedalaman $7 \mathrm{~m}$ sudah ditemukan tanah keras yang dapat digunakan untuk perencanaan pondasi tiang.

\section{DAFTAR PUSTAKA}

Sutaji, Hadi Imam. 2016. Identifikasi Jenis Batuan Bawah Permukaan Sebagai Kajian Awal Perencanaan Pembuatan Pondasi Bangunan Menggunakan Metode Resistivitas. Jurusan Fisika. Universitas Nusa Cendana Kupang.

Hakim, Arif Rahman, Hairunisa. 2017. Studi Struktur Bawah Permukaan Dengan Menggunakan Metode Geolistrik Resistivitas Konfigurasi Schlumberger.Jurnal Pemikiran Penelitian Pendidikan dan Sains. Vol. 5, No. 1.

Hurriyah, Raudatul Jannah. 2017. Analisis Struktur Lapisan Bawah Permukaan Menggunakan Metode Geolistrik (Studi Kasus Pada Kampus IIIIAIN Imam Bonjol Padang Di Sungai Bangek Kecamatn Koto Tangah).Skripsi IPA Fisika. Institut Agama Islam Negeri Imam Bonjol Padang Sumatera Barat.

Telford, W. M., dkk. 1990. Applied Geophysics.Second Edition.New York : Cambridge University Press.

Vebrianto, Suhendra. 2016. Eksplorasi Metode Geolistrik : Resistivitas, Polarisasi Terinduksi, dan Potensial Diri. Malang : UB Press. 